$\xi=-1$

\title{
Grease and its Application on Electrical Equipment: a Review
}

\author{
N Suhaila A Japar ${ }^{1}$, M Aizudin A. Aziz ${ }^{1}$, Mohd Najib Razali ${ }^{1}$, Nurul Waheeda Abdu Rahman ${ }^{1}$

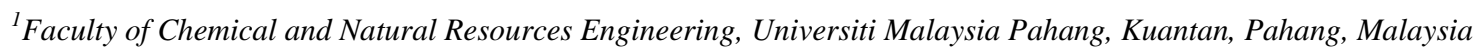 \\ *Corresponding author E-mail: maizudin@ump.edu.my
}

\begin{abstract}
Grease hardening and dry-out have been part of the major challenges in grease usage in electrical industry. The findings obtained over the years related to the study of synthetic, specialty, and new grease have found that the usage of these greases are costly; hence, it is very necessary to find an alternative method to reduce the cost as much as possible. Increasing petroleum demands, depletion of petroleum reserves, and the environmental awareness have influenced a huge interest in the use of waste oil as the alternative of base oil for grease formulation. The waste oils are considered as a promising candidate due the fact that the re-refining process of base oil is relatively cheap with high yield and the recovery of good quality oil. Optimum grease formulation is necessary in solving the aforementioned issues as well as overcoming complication specifically in the electrical industry where these greases are mainly utilized.
\end{abstract}

Keywords: Electrical equipment; Grease application; Grease formulation; Lubricating grease; Waste oil.

\section{Introduction}

Greases are semisolid lubricants that are utilized to reduce friction between two surfaces [1] as well as a protective film which allows the two touching surfaces to be separated. According to the American Society for Testing and Materials (ASTM), lubricating grease is defined as "a solid or semi-fluid lubricant consisting of a thickening agent in a liquid lubricant. Other ingredients imparting special properties may be included". Greases are commonly made of 85 to $90 \%$ base oil and 10 to $15 \%$ thickener. Hence, both the thickener fibers and the oil will resist deformation when stress is applied to grease, which respectively opposes the elastic and viscous forces [2].

Thickeners are dispersed in greases to produce a gel-like structure due to the fact that greases are made of lubricating oils. Lubricating grease does not flow and it shares the properties of solid at normal temperature, thus they are capable of maintaining their shape. However, the gel structure of grease will break down and flow normally like lubricating oils when the load is applied and the grease is heated. Most interestingly, grease is featured with reversibility that helps the flow of grease to stop and allows it to return to solid form when the load is removed [3]. However, lubricating greases will lose their solid properties when the load and temperature are applied to a critical value.

According to Watson [4], the first use of grease dates back to about 1400 B.C. and it was first introduced by the Ancient Romans and Egyptians. These greases were made from animal fats, resins, and lime. However, industrial development has come a long way since then which consequently led to the introduction of lithium, barium, and aluminum soap base greases in the 1920s and 1930s. The progressive industrial development has led to the establishment of complex base greases in the 1940s and 1950s. Therefore, complex base greases are slowly replacing the conventional greases due to its properties which include high temperature performance and good performance at moderate temperature.

The demand for environmental friendly products has always been a major point in any commercial sales. On top of that, both envi- ronmental legislation and consumer awareness have been impacting the design of lubricating grease. The original environmental friendly lubricant developed in the 1970s and 1980s was made to be applied on chainsaw and outboard motor applications [5]. A number of researches related to bio-lubricant grease have been performed by utilizing biodegradable raw material such as vegetable oil and base oil [6-8]. However, the development of biolubricant grease formulation was observed to be costly compared to the current grease available in the market; hence, it is considered to be impractical [9].

According to Lugt [10], advanced material technologies such as the implementation of nanotubes were also explored in the last decade. However, these types of technology do not exhibit any technological breakthrough in terms of functional performance apart from being commercially unpromising until the present time. Most of the existing researchers have focused on the development of grease performance or efficiency [11-13]. Nevertheless, there is a wide gap in the area of grease formulation related to the main components of grease that is largely made of crude oil (85\%-95\%) with recycled materials or waste products. The formulation process conducted using the downstream petroleum raw material is very expensive plus the permanent declining of petroleum resources.

Donley [14] further suggested that greases are formulated to perform the following key functions: (i) keep moving part apart, (ii) reduce friction, (iii) transfer heat (iv) carry away contaminants, (v) transmit power, (vi) protection, and (vii) corrosion prevention. Generally, grease can be categorized into several types based on its potential applications which include clay greases, extremepressure (EP) greases, soap-based grease, multi-purpose greases, and others. Lubricating grease has been widely utilized for numerous applications involving machinery and moving part, in which it functions as a sealant, provides protection against corrosion, and at the same time reduces noise and shock. 


\section{Page layout}

It is extremely crucial to note that lubricating grease and oil share no similarities. Grease is usually utilized when it is more practical to be used instead of lubricating oil. In this case, the type of lubricant used for a particular application is determined based on the equipment design and working conditions [15]. In general, lubricating grease is largely used in the heavy industry related to automotive, steel, and machinery as well as light industry involving food and textile.

\subsection{Automotive Industry}

For many years, conventional automotive greases were made from either aluminum, calcium, or sodium soaps based on the requirements dictated by the operating condition [16]. Take one case whereby EP greases that were utilized in automotive wheel bearing, chassis, disc brake, universal joints, and fifth wheel are either in the state of lithium or lithium complex, aluminum complex, and calcium sulfonate greases [17].

Meanwhile, lubricating grease selected in automotive industry should possess the following important properties: high dropping point, good shear stability and adhesive properties, thermal and oxidation degradation resistance, water resistance, good protection against heavy and continuous shock loads, anti-wear, good compatibility with other conventional greases and differential oils [18, 19]. On top of that, these properties are required to ensure that the grease is able to perform well during the operation. Lubricating greases of National Lubricating Grease Institute (NLGI) Consistency Grade 2 are often used in the automotive application due to their ability of remaining soft in cold weather.

\subsection{Steel industry}

In the case of steel industry, various types of greases were applied to different parts of machineries. The steel plant equipment is able to work under different operating parameters which include extreme heavy load to high speed as well as low to high temperatures [20]. Therefore, it is very crucial to properly select the most appropriate grease to ensure smooth operation and reliability of equipment. The greases used in steel industry are not particularly similar to those of automotive industry as they have high loadcarrying capacity, oxidation stability, mechanical stability, water wash resistance and good pumpability, and low cost for largevolume consumption [21]. In most cases, the grease is used to lubricate machinery with the operating temperature of less than $135{ }^{\circ} \mathrm{C}$ [19]. Other than that, EP multi-purpose greases that are comprised of lithium and aluminum complex soaps are normally utilized in steel mills.

Apart from that, the steel industry also adopts a wide variety of bearings that are lubricated with grease such as plain journal bearings which is especially beneficial and useful in rolling mill operations, rolling-element bearings, and table and roll neck bearings. On the other hand, the type of grease that are based on mineral oil used in hot and cold rolling equipment include conventional EP lithium greases, calcium complex greases, calcium sulfonate complex greases, lithium complex greases, and aluminum complex greases [16]. Finally, it should be duly noted that greases applied to these bearings will only be applied during the maintenance instead of the operation.

\subsection{Food Processing}

In the case of food processing, it is necessary for food-grade greases to comply with food, and health and safety regulations [10]. Hence, the common base oils that are suitable for this particular industry include white oils, polyalphaolefin (PAOs), some esters and vegetable oils $[20,22]$. On top of that, the common approved thickeners are aluminum stearate, aluminum complex, organoclay, and polyurea.

\subsection{Textile}

The utilization of lubricating grease in the textile industry is for the purpose of lubricating the textile machinery. It should be acknowledged that this industry prefers grease that are easier to clean and does not leave any stain to the textiles or fabrics. A number of grease products suitable for this industry usually contain additives that are able to assist in the process of removing oil stains from the fabric [20]. The common properties of greases used in the textile industry include load-carrying capacity, oxidation resistance, and good adhesion. Additionally, greases with rust preventive properties are also used due to the humid environment at the industry.

\subsection{Electrical Equipment}

The reliability of electric utility equipments such as connectors, switchgears, and circuit breakers are possible to be improved with modern lubrication technology and practices [23]. In recent years, various types of synthetic lubricants have demonstrated the ability to outperform conventional lubricants at extreme temperatures, resistance ability of grease dry out, and ability to protect against wear and corrosion which can lead to the failure of the equipment [24]. Electrical equipment installed in both industrial and commercial facilities can be exposed to both indoor and outdoor environments which are potentially detrimental to the metals used in electrical contacts including their coatings; therefore, it is very crucial to choose the most suitable lubricants to ensure the equipment is well protected.

In addition, lubricants are able to improve the performance of electrical contact by either reducing mating forces, extending the durability of plating, and enhancing the protection against corrosion [25]. However, the general principle of electrical equipment lubrication revolves around protecting the electrical connection from degrading which can further increase the electrical resistance [26]. Moreover, deposits on the contact surfaces formed by corrosion will definitely lead to the increase in contact resistant. Meanwhile, the application of lubricants in electrical contacts seems to provide protection from harsh environment, galvanic/fretting corrosion, and wear/friction, without interfering with the contacts' electrical resistance.

A wide range of lubricants have been tested on electrical contacts $[25,27,28]$. In the same token, Polyphenyl Ether (PPE) and Perfluorinated Polyether (PFPE) were discovered to possess hightemperature withstanding properties in comparison to other types of lubricants. Additionally, PPEs are also capable of providing protection from corrosion as well as increasing the life of connectors apart from having good thermal stability [29].

There are relatively few historical studies in the area of lubricating grease application in electrical equipment compared to other field of applications. Most researchers put their focus on the process of formulating grease with excellent conductivity. However, a number of problems were found related to the use of lubricating grease in electrical equipment such as long-term stability and high operating temperature. Most greases tend to evaporate at the temperatures over $100{ }^{\circ} \mathrm{C}$ [26] which then leads to the formulation of lubricating grease with excellent performance at extreme temperature.

\section{Issue of Grease Usage in Electrical Industry}

The application of lubricants is one of the ways to prevent any potential factors that can possibly increase the electrical resistance involving an electrical connection. The type and function of the contact determine the specific type of the required lubricant. In light of this, electrical contact can be defined as two surfaces that are in contact by force with the passage of electric current, voltage, or signals. The vast majority of published articles or journals on electrical lubrication have been observed to offer two strong recommendations [30] which are described as follow: (1) follow 
manufacturer's instruction, and (2) avoid mixing the lubricants Apart from that, several OEM recommendations also include engineering specifications, maintenance book, and documentation. The issues related to the need of following the guideline revolve around the difficulty to access the original manual that is included together with majority of hardware.

On top of that, there are several problems faced by the electrical industry related to the use of grease. In relation to this, it can be further described based on the issues faced by one of the electrical power industry in Malaysia which is related to their switchgears that were made of copper with or without silver plating. The switchgear often faces mechanical failure and electrical overloads at peak hours, which then leads to the elevation of temperature that will indirectly affect the grease. Apart from that, it was also observed that grease tends to experience major challenges in electrical contact lubrication which are dried-out and hardening. Grease dry-out and hardening are majorly the result of temperature effect during operation. Both low and high operating temperature can lead to grease hardening, but it is a different case for low temperature which is highly dependent on the type of base oil used in the formulation [15].

Moreover, there are several possible causes that can lead to the dry out and hardening of grease with respect to temperature effect Low viscosity base oil used in grease tends to have high risk of volatilization at high temperature due to the evaporation of oil from the matrix over time, which further results in the ratio of oilto-thickener to drop and to the hardening of grease [31]. Another cause of grease hardening can be explained by the oxidation of grease over time. It should be understood that both base oil and thickener in grease tend to have the possibilities to oxidize, but thickener is less prone to oxidation compared to base oil [15]

The buildup of oxidation products can be deleterious to thickener structure as well as cause the bleeding of oil particularly when grease is oxidized. High operating temperature can cause the oxidation rate to accelerate, which then cause carbonization that will definitely result in the progressive grease hardening and crust formation [32]. Not only that, it can also cause the increase of contact resistance which then reduces the contact reliability. Additionally, over-greasing can lead to oxidation since churning of grease may occur which finally results in energy loss and rising temperatures [33].

A research conducted by one of Malaysia's' electrical power industry team had managed to discover that grease applied to the contact area is capable of changing color (blueish green slurry and polymer-like) after a period of time. Generally, the discoloration of grease on the components generally indicates that oxidation is taking place, thus leading to the increase of contact resistance [34]. Another interesting finding is that lubricants may degrade as it reacts with the atmosphere and likely to polymerize when heated in the presence of a copper-based alloy [35]. Moreover, copper is known to degrade polymers through catalytic-enhanced oxidation; hence, it will definitely cause grease to change if it gets in contact with copper at elevated temperature [36] which will also induce copper corrosion. Therefore, it is important to utilize grease with a copper corrosion inhibitor as it may reduce lubricant-induced copper corrosion [37].

Nevertheless, several established studies have pointed out that grease hardening and dry-out can be avoided. Grease applied on contact surfaces are exposed to four temperature sensitive aging mechanisms, which are evaporation, surface migration, polymerization, and degradation $[30,38]$. However, lubricants may degrade by oxidation as well as form insulating films and increase contact resistance with time and temperature [39]. Therefore, it is extremely crucial to select proper grease formulation by referring to the electrical equipment design and operating conditions in order to avoid equipment or contact failure. Other than that, material properties such as viscosity, thermal stability, surface tension and vapour pressure are very important to be considered in order to select lubricating grease for electrical contact application [30].

Numerous types of greases were applied and tested by the team based on the greases recommended by manufacturers (OEM) for the purpose of electrical contact lubrication. However, the current practices seem to face several complications compared to normal operation due to the shortage of stocks. Hence, this further increases the need to acquire greases from different OEMs which can lead to the utilization of non-recommended contact grease. Along these lines, it can be safe to infer that not all kinds of greases are suitable for electrical contact application.

The contact between two metal surfaces is highly reliant on boundary lubrication. Hence, a very thin film of lubricant or additive, or both must be maintained to ensure that boundary lubrication is effective. This can be achieved by using various types of additive such as extreme pressure, anti-wear, and lubricity additives. Apart from that, solid lubricants, such as graphite, molybdenum disulfide, and PTFE may also be added by the lubricant manufacturer. However, both PTFE and molybdenum disulfide seem to have the possibility to increase in wear [40].

\section{Electrical Contact Grease}

The lubrication of separable electronic connector can be described as the practice of coating contact surfaces with the purpose of reducing mechanical wear and friction as well as degradation caused by fretting. Meanwhile, lubricants are described as thin metallic film, fluids, greases, and solid. In relation to that, this review has chosen to focus on the use of grease to lubricate the electrical contact surfaces. Grease is defined as a threedimensional (3D) matrix soap fibers dispersed throughout a liquid lubricant. In other words, it can be considered similar to a sponge soaked with liquid that will flow as a result of applying shear stress exceeding the yield point. The base oil is bonded by the following factors: (1) capillary forces, (2) mechanical occlusion, or (3) molecular attraction between polar region on soap fibers and base oil molecules [41].

The contact surfaces were not flat in contact operation even when force is applied, and the two surfaces do not touch at all points [42]. Grease lubricating mechanisms can be described as oil reservoir that is slowly released (bleeding) into the contact surface. However, some believe that the oil is released by the destruction of thickener fibers instead of bleeding. In contact surface lubrication, the initial filling is believed to play a major role [43]. However, over-greasing may eventually lead to excessive churning, elevation of temperature, and severe grease degradation. This finding is constant to the finding of Zhang [44] which states that the appropriate thickness of lubrication film is the most influential factor on inhibition from corrosion and wear, which is also capable of reducing the possibility of contact failure.

According to Campbell [45], grease viscosity is limited to the speed of slide and the lowest temperature in service. In this case, petroleum-based grease is believed to work effectively provided that the bearing component is fully rotated continuously at a specified speed. However, it stays static in circuit breaker, while partial rotation and movement tend to occur during operation [46]. In addition, petroleum-based grease does not perform well in extreme temperature and dirty environment. Hence, the grease will end up breaking down and becoming acidic, which then forms a layer of varnish on the contact surface. In line with Slade's statement [47], mineral oil is often expected to protect contact surface from tarnishing but the opposite tends to occur over time. Mineral oil is mostly derived from the refining of crude oil (petroleum), and even a highly refined mineral oil is known to contain sulphur compound which is extremely corrosive. Therefore, plating the metal contact surface can slow down the build-up of resistive film in mineral oil environment. A research carried out by Arnell and Andersson [48] had found that the low contact resistance on copper plated with silver contact in mineral oil can be maintained by applying solid lubricant to the contact.

Furthermore, electrical contact resistance which is caused by electrical constriction tends to reduce the volume of material used, whereas film resistance tends to increase the contact resistance due to the presence of contamination film. The contamination film 
that is known to be mechanically brittle may be caused by the formation of oxides or corrosion product on contact surface, which has the possibility to increase contact resistance and reduce contact reliability. However, electrical contact can be established when the film is fractured and metal-to-metal contact spot is formed by metal extrusion through the layer's crack [47]. Electrical constriction can be reduced by applying more load due to the fact that contact resistance is inversely exponential to load applied. In regard to this, the practice of contact lubrication is as old as connectors themselves [28]. The capability of lubricants to stabilize contact resistance, reduce wear, and delay the oxidation rate by protecting the metal surface from the environment is apparently not dependent on the lubricants composition and viscosity [49]. Several lubricants such as polyphenyl ethers were discovered to be more potent in inhibiting adhesive wear. However, mineral oil and polyolester are not potent to reduce the friction coefficient as a result of lower viscosity [25], including the earlier statement that describes the potential of mineral oil in causing corrosion on contact surfaces. Moreover, greases formulated using mineral oil are more prone to evaporation compared to synthetic greases, and they tend to separate from thickeners over time. However, the cost of synthetic grease is expensive compared to the conventional grease. The results provided by established studies related to the electrical contact grease formulation are displayed in Table 1. It can be observed that many contact greases possess beneficial effect on the contact resistance behavior. A vast majority of the studies show that the grease application helps in reducing the contact resistance. In spite of that, previous research on contact grease mainly focused on base oil and thickeners, and less on additive. On top of that, most of the current researchers put their concern on the use of different type of compositions of the grease in order to prevent wear and friction, along with the importance of providing excellent conductivity capacity and reducing contact resistance. However, lubrication was confirmed to only be able to delay fretting corrosion instead of totally prevent it from happening [50].

Table 1: Lubrication test for various grease types in electrical contact

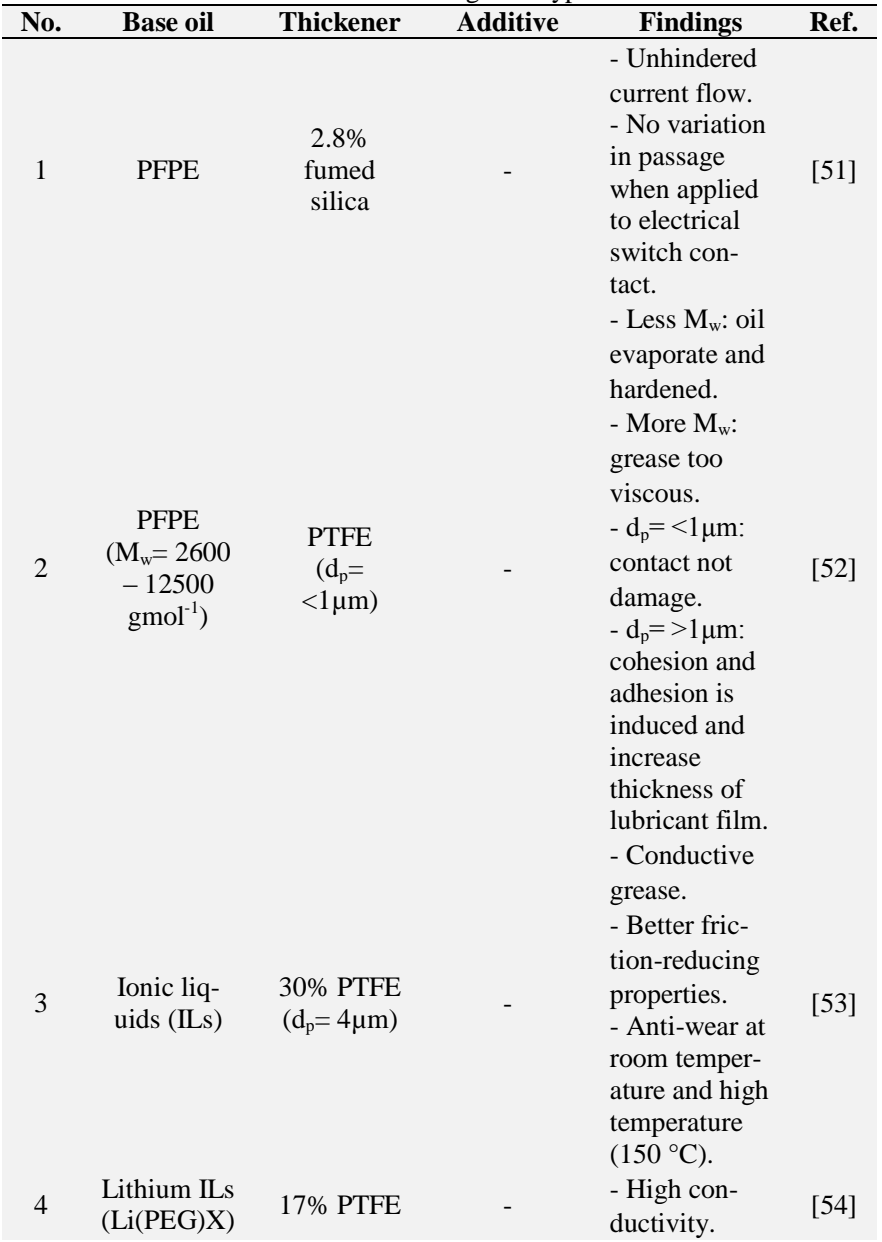

\begin{tabular}{|c|c|c|c|c|c|}
\hline & & & & $\begin{array}{l}\text { - Excellent } \\
\text { tribological } \\
\text { properties. } \\
\text { - Self- } \\
\text { lubricating } \\
\text { abilities. } \\
\text { - Long service } \\
\text { life }\end{array}$ & \\
\hline 5 & PAO & $\begin{array}{c}\mathrm{LiOH}, \\
\text { sebacic } \\
\text { acid, and } \\
\text { 12-hydroxy } \\
\text { stearic acid }\end{array}$ & $\begin{array}{c}\text { Polyaniline } \\
\text { (PAN) } \\
\text { powder } \\
\left(\mathrm{d}_{\mathrm{p}}=1-10\right. \\
\mu \mathrm{m})\end{array}$ & $\begin{array}{l}\text { - Excellent } \\
\text { tribology } \\
\text { performance } \\
\text { and conduc- } \\
\text { tive capacity. } \\
\text { - Low contact } \\
\text { resistance. }\end{array}$ & [55] \\
\hline 6 & PAO & $\begin{array}{c}\text { PTFE } \\
\left(d_{p}=4 \mu \mathrm{m}\right)\end{array}$ & $\begin{array}{l}\text { ATO na- } \\
\text { nometer } \\
\text { powder }\end{array}$ & $\begin{array}{l}\text { - Excellent } \\
\text { conductive } \\
\text { capacity. } \\
\text { - Low contact } \\
\text { resistance. } \\
\text { - Better fric- } \\
\text { tion-reducing } \\
\text { and anti-wear } \\
\text { properties. }\end{array}$ & [56] \\
\hline 7 & PAG & $\begin{array}{c}\text { PTFE } \\
\left(\mathrm{d}_{\mathrm{p}}=4 \mu \mathrm{m}\right)\end{array}$ & CNTs & $\begin{array}{l}\text { - Improved } \\
\text { conductive } \\
\text { capacity. } \\
\text { - Improved } \\
\text { friction and } \\
\text { reducing and } \\
\text { anti-wear } \\
\text { abilities }\end{array}$ & [57] \\
\hline & $\begin{array}{l}\text { Perflu } \\
\text { fluort }\end{array}$ & $\begin{array}{l}\text { lyether; } \\
\text { ene; CNT }\end{array}$ & PAO-Polyc & $\begin{array}{l}\text { haolefin; } \\
\text { ube; } A T O-A n\end{array}$ & $\begin{array}{l}\text { TFE- } \\
\text { nony }\end{array}$ \\
\hline
\end{tabular}

\section{Grease Formulation for Electrical Equip- ment}

In this review, two main factors have been considered for the purpose of formulating electrical contact grease, which are the cost and problem related to the electrical industry. As has been previously stated, there exists a huge gap in the area of grease formulation. The formulation process that utilizes the downstream petroleum raw material is deemed to be expensive. In addition, the use of petroleum product in lubricant has been observed to generate several drawbacks to the contact surfaces. On top of that, it was found that synthetic grease, specialty grease, and new base oil developed for electrical equipment are more expensive compared to the traditional grease; hence, it is necessary to find an alternative method to cut down the grease production cost.

\subsection{Base Oil: From Crude Oil to Waste Oil}

The formulation of lubricating grease commonly involves the use of petroleum or synthetic mineral oil as the base oil, but the importance of acknowledging environmental awareness has led to the establishment of more strict policies on the use of nonenvironmental friendly sources. In relation to this, the development and application of environmental friendly lubricating grease have started to gain attention but it is undeniable that eco-friendly base oil such as biodegradable synthetics ester is deemed costly. Therefore, the continuous search for the best and suitable ecofriendly product that can replace mineral oil in various industrial applications is very important, particularly in the fuel and energy sector. Hence, renewable resources such as vegetable oil and their derivatives are considered as the potential replacements for mineral oil base stock in certain lubrication application, especially in the formulation of lubricating grease [60].

The recent crude oil production has been experiencing a massive decline worldwide. In Asia-Pacific, the decline was observed to be substantially greater compared to the production pullbacks in other 
parts of the world [61]. In this, case, it is forecasted that the AsiaPacific crude oil production will fall by 1 million barrels per day by 2020 which is caused by the decline of Asia-Pacific major oil producers, namely China, Indonesia, Malaysia, and Thailand.

Apart from that, vegetable oil is also well known for its biodegradability. Most of the commercial production of vegetable oil mainly revolves around for food purposes. Vegetable oils have been considered as a result of their advantages which include high viscosity index, high lubricity, and low volatility among other oils [7]. However, it is not recommended to utilize this source in the formulation of grease because it can definitely pose a negative effect on the food market. In addition, a huge number of researchers have tried to develop vegetable-oil-based derivatives which possess a nearly similar properties and performance to the petroleumbased diesel oil. However, the process involves a very high manufacturing cost. Following this, waste cooking oil was then claimed to be the suitable alternative for vegetable oils. However, it is no longer recommended to be used in food industries due to toxic build up after being heated as well as the change of oil physical properties [62,63].

The used lubricating oil or waste oil is normally generated from the crankcase of internal combustion engines (mainly run on petrol or diesel). Apart from that, used oil is also produced and collected from other operating equipment such as hydraulic oil or gear and transmission oils [64]. However, lubricating oil becomes unfit for further utilization as a result of the accumulation of contaminants in the oil as well as the chemical changes in the oil. On top of that, the disposal, dumping, and uncontrolled burning of used oil can harmfully threaten the environment by causing severe pollution. According to the European Environmental Policy [65] on the Directive for the disposal of waste oil, it can be said that the regeneration of waste oil (producing base oils) is highly encouraged instead of the usual disposal in order to reduce the disposal amount of oil which indirectly keep the environment safe [66]. Audibert [67] states that the re-refining of oil is able to produce one-to-one ratio of new oil production which further suggests that the production of re-refined oil is also able to reduce the number of new oil produced. A study conducted by Mensah-Brown [68] shows that a total of $73.3 \%$ oil is recovered from the re-refining process of used oil, which agrees with the fact that oil can be recycled to yield lube stock to produce lubricants and sustain crude petroleum.

All in all, the study on recycled used oil, high cost of grease production, and issues related to the environmental conservation have brought a wide and promising interest in the use of waste oil as the best potential replacement for base oil in electrical contact grease production as well as possible methods that can be applied to cut the cost. It is further believed that the use of waste oil in grease formulation will be more economic because the re-refining process is relatively cheap compared to virgin base oil stock [68] Apart from that, it also helps to prevent unreasonable dumping of used oil which can definitely save the environment from being extremely polluted.

\subsubsection{Waste Oil Treatment}

The conventional method on the re-refining technologies for waste oil requires the vacuum distillation process which concentrates the contaminants in the vacuum residue. It is important to note that the conventional acid/clay re-refining process has been utilized for quite a number of years, but the process is not eco-friendly due to the large production of pollutant. This method is also incapable to re-refine the modern lubricating oil such as multi-grade engine oils $[69,70]$. In relation to this, many acid/clay re-refining plant were shut down in 1980s [71] as a result of the increased environmental awareness, which subsequently lead to the development of improved re-refining technologies for both environmental and product quality reasons.

Furthermore, the study on the regeneration of used oil continues to develop with better emphasis on ensuring that the processes are environmentally friendly. The research performed by Hamawand
[70] shows that glacial acetic acid was used to replace sulfuric acid in the method of acid/clay re-refining. This method is considered suitable because it involves a lower cost process as a result of using low-cost acid as well as moderate conditions of the process. On top of that, this process does not emit poisonous gases and pose minimum negative impact on the processing equipment.

In regard to this, the solvent extraction technique was later developed to replace the acid treatment. The basic of this pretreatment can be described based on the use of a solvent to selectively extract the base oil components from the used oil in a process that is regarded to be quite similar to the commonly used process adopted in crude oil refining for the purpose of separating asphaltenes [69, 70, 72, 73]. Generally, ketones and alcohols have been widely used as solvents, while the oil generated from this process is as good as to that produced through the acid/clay method. However, this method is costly due to the need of utilizing expensive solvents and vacuum distillation. Recently, hydrocarbon such as propane has been used as solvent $[70,71,74]$ due to its ability to dissolve paraffinic or waxy material and intermediately dissolve oxygenated material.

As stated by Dang [69], the existing re-refining processes involve three basic steps which are settling, solvent chemical treatment or vacuum distillation, and finishing by hydrotreating or clay contact. Several variations and combination of processes have been developed for the purpose of lube re-refining over a period of time such as the Kinetics Technology International (KTI) process, which is a combination of vacuum distillation and hydro-finishing [75]. This technology is able to produce high quality base oils with a yield of approximately $82 \%$ as well as to minimize the pollution cause by the by-products.

\subsection{Thickeners}

The function of thickeners is to provide a physical matrix that can hold the base fluid in a solid structure until the operating conditions such as load, shear, and temperature are able to initiate viscoelastic flow in the grease. Hence, a careful balance of solubility between the base fluid and the thickener is required in order to achieve this matrix. In other word, thickener is an agent that is capable of changing the phase from fluid to semi solid.

The two principal groups of thickeners can be divided into two: metal soaps non-metal soap. Soap-based greases are by far the most widespread lubricants because metal soap consists of a longchain fatty acid neutralized by metal such as lithium, sodium, calcium, aluminum, and others. Meanwhile, inorganic, organic, and synthetic materials are used as thickeners in non-soap greases. Nevertheless, non-soap grease has managed to gain popularity in high-temperature environments. However, under elevated temperatures, base oil will eventually oxidize even though the thickeners are able to withstand high temperature, which requires a frequent relubrication interval [15].

\subsection{Additives}

The purpose of adding additives to some grease is to improve their lubricating properties. Moreover, additive also plays an important role in protecting grease and lubricated surfaces apart from its ability to enhance the grease performance. Additives may constitute 0 to 15 percent of the total grease mass; hence, it is added to increase additional properties such as anti-oxidation, rust prevention, anti-wear, and pressure resistance. A wide range of additives can be used to improve grease performance, whereby molybdenum disulphide $\left(\mathrm{MoS}_{2}\right)$ have gained interest in this review because it has high load-carrying capacity and excellent in both low and high temperature[15].

The use of $\mathrm{MoS}_{2}$ is very beneficial in the boundary lubrication regime based on the presence of metal to metal contact, which is contrasting to the hydrodynamic regime where the presence of sufficiently thick fluid film is able to prevent asperity contact and any virtual wear [76]. $\mathrm{MoS}_{2}$ can be described as an anisotropic transition metal dichalcogenide (TMD) compound material with a 
trigonal prismatic structure that is comprised of a layer of molybdenum atoms between two layers of sulphur atoms that are loosely bounded by Van der Waals interaction [77].

The electrical properties of $\mathrm{MoS}_{2}$ are of significant practical importance, particularly in electrical application. Various parameters are able to potentially correlate with $\mathrm{MoS}_{2}$ resistivity, but both the temperature and level of impurities are considered to be of a higher significant [78]. On top of that, there is no clear agreement on electrical conductivity of $\mathrm{MoS}_{2}$, but a strong correlation seem to exist between $\mathrm{MoS}_{2}$ conductivity and temperature [79]. In relation to this, $\mathrm{MoS}_{2}$ electrical conductivity tend to increase with temperature as the resistivity decreases [78]. In short, it is safe to conclude that $\mathrm{MoS}_{2}$ is very versatile to be used as additive in the formulation of electrical contact grease due to its high temperature withstanding properties and good electrical conductivity.

\section{Conclusion}

In general, it has been observed that research on grease for electrical equipment is still ongoing and most of the current researchers tend to focus on the optimization of grease performance or efficiency. In addition, it is fully noted that the current development of grease for electrical equipment which include synthetic, specialty, or new finding is deemed to be very expensive. Moreover, the study on waste oil regeneration has been conducted since the 1930 s due to the environmental issues caused by the waste oil. The present review further covers grease application on electrical equipment, including grease production performed using waste oil for electrical contact. Most of the challenges in this field are related to the need of finding the optimum formulations that is very necessary in producing lubricating grease which can be applied for specific type of electrical contact. Finally, the advancement of lubricating grease which utilizes used oil can lead to major revolution in the world of lubricant market because this idea is believed to be effective in reducing the cost and environmental impact related to grease manufacturing.

\section{Acknowledgement}

The researchers would like to extend their gratitude to Universiti Malaysia Pahang (UMP) for providing the grants for this study under the grant number RDU160382.

\section{References}

[1] Abdulbari HA, Rosli MY, Abdurrahman HN \& Nizam MK, Lubricating grease from spent bleaching earth and waste cooking oil : Tribology properties. International Journal of the Physical Sciences, Vol.6, No.20, (2011), pp.4695-4699, http://dx.doi.org/10.5897/IJPS11.561

[2] Laurentis ND, Kadiric A, Lugt P \& Cann P, The influence of bearing grease composition on friction in rolling/sliding concentrated contacts, Tribiology International, Vol.94, (2016), pp.624-632, http://dx.doi.org/10.1016/j.triboint.2015.10.012

[3] Ischuk YL, Lubricating Grease Manufacturing Technology, New Age International (P) Limited, (2006), pp.11.

[4] Watson D, Grease, The Forgotten Lube, Tow Professional, (2014), available online: http://towprofessional.com/article/grease-theforgotten-lube/, last visit:23.11.2016

[5] Sharma BK \& Biresaw G, Environmentally Friendly and Biobased Lubricants, CRC Press, (2016).

[6] Gawrilow I, Vegetables oil usage in lubricant, International News on Fats, Oils and Related Materials, Vol.15, No.11, (2004), pp.702-705.

[7] Srivastava A \& Sahai P, Vegetable oils as lube basestocks: A review, African Journal of Biotechnology, Vol.12, No.9, (2013), pp.880-891, http://dx.doi.org/10.5897/AJB12.2823

[8] El-Adly RA, Bedier AH, Hussein MF, Ismail EA \& El-emary MM, Jojoba and castor oils as fluids for the preparation of bio greases: a comparative study, International Journal of Scientific \& Engineering Research, Vol.5, No.6, (2014), pp.755-762.
[9] Gokhale R \& Karmarkar AS, Emerging trends and benefits of biolubricants, Chemical Engineering World Magazine, Vol.47, No.6, (2012), pp.63-64.

[10] Lugt PM, Modern advancements in lubricating grease technology, Tribology International, Vol.97, (2016), pp.467-477, http://dx.doi.org/10.1016/j.triboint.2016.01.045

[11] Cheng ZL \& Qin XX, Study on friction performance of graphenebased semi-solid grease, Chinese Chemical Letters, Vol.25, No.9, (2014), http://dx.doi.org/10.1016/j.cclet.2014.03.010

pp.1305-1307,

12] Gonçalves D, Graça B, Campos AV, Seabra J, Leckner J \& Westbroek R, Formulation, rheology and thermal ageing of polymer greases-Part I: Influence of the thickener content, Tribology International, Vol.87, (2015), pp.160-170, http://dx.doi.org/10.1016/j.triboint.2015.02.018

[13] Sommer M \& Haas W, A new approach on grease tribology in sealing technology: Influence of the thickener particles, Tribology International, Vol.103, (2016), pp.574-583, http://dx.doi.org/10.1016/j.triboint.2016.08.002

[14] Donley E, Handbook of Advances in Additive Lubricants and Grease Technology, Auris Reference, (2012).

[15] Lansdown AR, Lubrication and lubricant selection: a practical guide, ASME Press, (2004).

[16] Dresel W \& Heckler R-P, Ullmann's Encyclopedia of Industrial Chemistry, Vol.21, Wiley, (2012), pp.547-571.

[17] Kumar A, Humphreys S \& Mallory B, Overbased calcium sulfonate greases for extreme environment, A Quarterly Journal of NLGIIndia Chapter, Vol.15, No.3, (2012), pp.5-12.

[18] Antony JP, Mishra GS, Nagar SC, Kumar A, Naithani KP, Mehta AK, Ghosh S \& Raje NR, An Improved Multipurpose Grease For Automotive Applications, SAE Technical Paper 2004,28-0082, (2004), pp.1-8, http://dx.doi.org/10.4271/2004-28-0082

[19] Rizvi SQA, A Comprehensive Review of Lubricant Chemistry, Technology, Selection, and Design. ASTM International, (2008)

[20] Mortier RM, Fox MF \& Orszulik S, Chemistry and Technology of Lubricants, Springer Netherlands, (2011).

[21] Pradhan K \& Kumar A, Steel Plant Lubrication, (2015).

[22] Gebarin S, The Basics of Food - grade Lubricants, (2009).

[23] Finner GM, Advanced lubrication technology \& application strategy for improved outdoor high voltage electrical equipment reliability, 2010 IEEE PES Transmission and Distribution Conference and Exposition: Smart Solutions for a Changing World, (2010), http://dx.doi.org/10.1109/TDC.2010.5484536

[24] Mclain J, Synthetic Greases Gain Wider Appeal, (2007)

[25] Chudnovsky BH, Lubrication of electrical contacts, Electrical Contacts, Proceedings of the Annual Holm Conference on Electrical Contacts, (2005), http://dx.doi.org/10.1109/HOLM.2005.1518230

[26] Song J, Wang L, Zibart A \& Koch C, Corrosion protection of electrically conductive surfaces, Metals, Vol.2, No.4, (2012), pp.450477.

[27] Braunovic M, Myshkin NK \& Konchits VV, Electrical Contacts: Fundamentals, Applications and Technology, CRC Press, (2006).

[28] Holm E, Williamson JBP, \& Holm R, Electric Contacts: Theory and Application, Springer Berlin Heidelberg, (2013).

[29] Rudnick L, Synthetics, Mineral oils, and bio based lubricants, CRC Press, (2013).

[30] Chudnovsky BH, Electrical Power Transmission and Distribution: Aging and Life Extension Techniques, Taylor \& Francis, (2012).

[31] Fitch J, Grease Dry-out: Causes, Effects and Remedies, Noria: Machimery Lubrication, (2011), available online: https://www.machinerylubrication.com/Read/28517/grease-dry-outcauses, last visit: 04-02-2017

[32] Marume C, Elemental Determination of Lubricating Grease Using ICP-OES, (2014).

[33] Noria Corporation, The Dangers of Overgreasing, Noria: Machinery Lubrication, (2011), available online: https://www.machinerylubrication.com/Read/28664/dangers-ofovergreasing-, last visit:31.03.2017

[34] Serna P, Lubrication: extend the life of circuit breakers and switches, SigmaSix Solution, (2015), available online: http://www.nwhydro.org/wpcontent/.../12_Sigma_Six_LubCrctBrkrsSwtchs.pdf, last visit: 31.03.2017

[35] Chudnovsky BH, Transmission, Distribution, and Renewable Energy Generation Power Equipment: Aging and Life Extension Techniques, Second Edition, CRC Press, (2017).

[36] Gagnon D \& Braunovic M, High temperature lubricants for power connectors operating at extreme conditions, Proceedings of the Forty-Eighth IEEE Holm Conference on Electrical Contacts, 
(2002),

pp. $273-282$

http://dx.doi.org/10.1109/HOLM.2002.1040851

[37] Mccarthy SL, Carter R \& Weber WH, Lubricant-induced corrosion in copper electrical contacts, Electrical Contacts-997 Proceedings of the Forty-Third IEEE Holm Conference on Electrical Contacts, (1997), pp.115-120, http://dx.doi.org/10.1109/HOLM.1997.638003

[38] Antler M, Electronic connector contact lubricants: the polyether fluids, IEEE Transactions on Components, Hybrids, and Manufacturing Technology, Vol.10, (1987), pp.32-41, http://dx.doi.org/10.1109/TCHMT.1987.1134716

[39] Shpenkov GP, Tribology Series: Friction Surface Phenomena, Elsevier Science, (1995), pp. 217-250.

[40] Bagi S \& Aswath P, Mechanism of friction and wear in $\mathrm{MoS}_{2}$ and ZDDP/F-PTFE greases under spectrum loading conditions, Lubricants. Vol.3, No.4, (2015), pp.687-711. http://dx/doi.org/10.3390/lubricants3040687

[41] Donahue CJ, Lubricating grease: a chemical primer, Journal of Chemical Education, Vol.83, No.6, (2006), pp.862-869.

[42] Antler M, Effect of Surface Contamination on Electric Contact Performance, IEEE Circuits Devices Magazine, Vol.3, No.2, (1987), pp.8-20, http://dx.doi.org/10.1109/MCD.1987.6323234

[43] LUBEWHIZ, Lubricating Mechanism of Greases, (2017), available online: http://www.lubewhiz.in/how_grease_works.html, last visit: 29.03.2017

[44] Zhang JG, The application and mechanism of lubricants on electrical contacts, Proceedings of IEEE Holm Conference on Electrical Contracts, (1994), pp.145-154.

[45] Campbell W, The lubrication of electrical contacts, IEEE Transactions on Components, Hybrids, and Manufacturing Technology, Vol.1, (1978), pp.4-16.

[46] Salinas AR \& Pruente J, Enhancing circuit breaker reliability through effective mechanism maintenance and lubrication, 2001 IEEE/PES Transmission and Distribution Conference and Exposition. Developing New Perspectives, Vol.1, (2001), pp.578-587.

[47] Slade PG, Electrical Contacts: Principles and Applications, Taylor \& Francis, (2013).

[48] Arnell S \& Andersson G, Silver iodide as a solid lubricant for power contacts, Proceedings of the Forth-Seventh IEEE Holm Conference on Electrical Contacts, (2001), pp.239-244.

[49] Antler M, Survey of contact fretting in electrical connectors. IEEE Transactions on Components, Hybrids, and Manufacturing Technology, Vol.8, No.1, (1985), pp.87-104, http://dx.doi.org/10.1109/TCHMT.1985.1136462

[50] Van Dijk P, Some effects of lubricants and corrosion inhibitors on electrical contacts, AMP Journal of Technology, Vol.2, (1992), pp.56-62.

[51] Schweigkofler M \& Schmidt M, Perfluoropolyether, (2014)

[52] Sato T, Sato K, Morita A, Tsuchiya K, Kanno T \& Nitta T, Grease for electrical contact and slide electricity structure, power switch, vacuum circuit breaker, vacuum-insulated switchgear assembling method, (2012).

[53] Wang Z, Xia Y, Liu Z \& Wen Z, Conductive lubricating grease synthesized using the ionic liquid, Tribology Letters, Vol.46, No.1, (2012), pp.33-42, http://dx.doi.org/10.1007/s11249-012-9915-x

[54] Fan X, Xia Y \& Wang L, Tribological properties of conductive lubricating greases, Friction, Vol.2, (2014), pp.343-353, http://dx.doi.org/10.1007/s40544-014-0062-2

[55] Chen J, Xia Y, Hu Y \& Hou B, Tribological performance and conductive capacity of Ag coating under boundary lubrication, Tribology International, Vol.110, (2017), pp.161-172, http://dx.doi.org/10.1016/j.triboint.2017.02.006

[56] Ge X, Xia Y, Shu Z \& Zhao X, Conductive grease synthesized using nanometer ATO as an additive, Friction, Vol.3, (2015), pp.5664, http://dx.doi.org/10.1007/s40544-015-0073-7

[57] Ge X, Xia Y \& Feng X, Influence of carbon nanotubes on conductive capacity and tribological characteristics of poly(ethylene glycol-ran-propylene glycol) monobutyl ether as base oil of grease, Journal of Tribology, Vol.138, No.1, (2016), pp.1801, http://dx.doi.org/10.1115/1.4031232

[58] Acton QA, Solvents-Advances in Research and Application: 2012 Edition, ScholarlyEditions, (2012).

[59] Somers AE, Howlett PC, Macfarlane DR \& Forsyth M, A review of ionic liquid lubricants, Lubricants, Vol.1, (2013), pp.3-21.

[60] Sharma BK, Adhvaryu A, Perez JM \& Erhan SZ, Biobased grease with improved oxidation performance for industrial application. Journal of Agricultural and Food Chemistry, Vol.54, No.20, (2006), pp.7594-7599.

[61] Forest D, Oil Production Here Is Declining Faster Than Anywhere On Earth, (2017), available online: https://oilprice.com/Energy/Crude-Oil/Oil-Production-Here-Is-
Declining-Faster-Than-Anywhere-On-Earth.html, last visit:11.03.2017

[62] Clark WL \& Serbia GW, Safety aspects of frying fats and oils. Food Technology, Vol.45, (1991), pp.84-94.

[63] Kulkarni MG \& Dalai AK, Waste cooking oil an economical source for biodiesel: a review, Industrial \& Engineering Chemistry Research, Vol.45, (2006), pp.2901-2913.

[64] ROSE, MSDS Used Lubricating Oil.

[65] IEEP, Manual of European Environmental Policy, (2014)

[66] Kajdas C, Major pathways for used oil disposal and recycling, Tribotest Journal, Vol.7, (2000).

[67] Audibert F, Waste Engine Oils: Rerefining and Energy Recovery, Elsevier Science, (2011).

[68] Mensah-Brown H, Re-refining and recycling of used lubricating oil: An option for foreign exchange and natural resource conservation in Ghana, ARPN Journal of Engineering and Applied Sciences, Vol.10, No.2, (2015), pp.797-801.

[69] Dang GS, Rerefining of used oils - a review of commercial processes, Tribotest Journal, Vol. 3, (1997), pp.445-457.

[70] Hamawand I, Yusaf T \& Rafat S, Recycling of waste engine oils using a new washing agent, Energies, Vol.6, (2013), pp.1023-1049.

[71] Giovanna FD, Khlebinskaia O, Lodolo A \& Miertus S, Compendium of Used Oil Regeneration Technologies, (2003).

[72] Hussein M, Amer AA \& Gaberah AS, Used lubricating oils rerefining by solvent extraction, American Journal of Environmental Engineering and Science, Vol.1, No. 3, (2014), pp.44-50.

[73] Rincon J, Canizares P \& Garcia MT, Regeneration of used lubricant oil by polar solvent extraction, Industrial \& Engineering Chemistry Research, Vol.44, No.12, (2005), pp.4373-4379.

[74] Jesusa R, Canizares P, Garc1 MT \& Gracia I, Regeneration of used lubricant oil by propane extraction, Industrial \& Engineering Chemistry, Vol.42, No.20, (2003), pp.4867-4873.

[75] Srivastava SP, Development in Lubricant Technology, John Wiley \& Sons, Inc., (2014), pp. 299-307.

[76] Nehme G, The effect of cyclic speed on the wear properties of molybdenum disulfide greases under extreme pressure loading using 4 balls wear tests, International Journal of Mechanical, Aerospace, Industrial, Mechatronic and Manufacturing Engineering, Vol.7, No.11, (2013), pp.2165-2170.

[77] Gu SY, Gao XF \& Zhang YH, Synthesis and characterization of solvent-free ionic molybdenum disulphide $\left(\mathrm{MoS}_{2}\right)$ nanofluids. $\mathrm{Ma}$ terials Chemistry and Physics, Vol.149, (2015), pp.587-593, http://dx.doi.org/10.1016/j.matchemphys.2014.11.012

[78] Epshteyn Y \& Risdon T, Molybdenum disulfide in lubricant applications-a review, 12 Lubricating Grease Conference, (2010), pp. $2-12$.

[79] Lansdown AR, Molybdenum Disulphide Lubrication, Elsevier Science, (1999) 